\title{
Interface computacional 3D para biofeedback multimodal em tempo real
}

\author{
Angela Abreu Rosa de Sá*, Alcimar Barbosa Soares
}

Resumo Este artigo descreve o projeto de um sistema computacional em tempo real para biofeedback multimodal. As informações biológicas ou psico-fisiológicas do paciente são detectadas por sensores específicos e processadas para prover feedback visual, por meio de ambientes virtuais tridimensionais e feedback auditivo. O dispositivo foi projetado para coleta e tratamento de seis sinais distintos: EMG, EEG, GSR, temperatura, frequência cardíaca e frequência respiratória. O aplicativo de software foi projetado em linguagem Visual $\mathrm{C}^{++}$e utiliza técnicas de programação concorrente para permitir o tratamento adequado de todas as ações em tempo real. Os ambientes virtuais foram criados no software 3D Studio Max $^{\circledR}$ e renderizados utilizando os recursos da biblioteca gráfica Direct $\mathrm{X}^{\circledR}$ da Microsoft Corp. O sistema desenvolvido resultou, conforme relatos dos voluntários, em sessões agradáveis e interessantes, que permitiam a escolha de diferentes tipos de ambientes virtuais capazes de se adequar às necessidades individuais. Todos os dados coletados durante as sessões de biofeedback são armazenados em um banco de dados específico, possibilitando a geração de relatórios para o terapeuta e permitindo o acompanhamento da evolução dos pacientes ao longo do tratamento. O sistema possui potencialidade para utilização como apoio ao tratamento de diversas patologias e disfunções, como demonstrado pelos experimentos realizados nas diferentes modalidades de biofeedback. Com este trabalho, os autores esperam ainda contribuir para o desenvolvimento de know-how nacional na área, à medida que disponibilizam técnicas avançadas para produção de hardware e software aplicáveis a tratamentos em biofeedback multimodal.

Palavras-chave Biofeedback multimodal, Tempo real, Terapia comportamental.

\section{D computer interface for real time multimodal biofeedback}

Abstract This article describes the design of a real-time multimodal biofeedback system. Biological or psychophysiological information from the patients are detected by specific sensors and processed to provide visual feedback, by means of three-dimensional virtual environments and auditory feedback. The device has been designed to capture up to six biomedical signals: EMG, EEG, GSR, temperature, heart rate and respiratory rate. The software was designed using Visual $C^{++}$and uses concurrent programming techniques to allow proper treatment of all actions in real time. The virtual environments have been created with $3 D$ Studio $M a x^{\circledR}$ and rendered using the resources of the Direct $X^{\circledR}$ graphics library from Microsoft Corp. The developed system resulted, according to reports from volunteers, in enjoyable and interesting sessions, allowing the selection of different types of virtual environments able to adapt to individual needs. All data collected during the biofeedback sessions are stored in a specific database, allowing the generation of reports to the therapist and enabling him to monitor the progress of the patients throughout the treatment. The system has great potential to be uses as a supporting tool for the treatment of various diseases and disorders, as demonstrated by experiments performed on different types of biofeedback. Also, with this work, the authors hope to contribute to the further development of national expertise in the area, as they provide advanced techniques for the production of hardware and software applied to multimodal biofeedback treatments.

Keywords Multimodal biofeedback, Real time, Behavioral therapy. 


\section{Introdução}

O corpo humano está constantemente sujeito a receber estímulos variados, sejam eles externos (alterações climáticas, impactos físicos etc.), bioquímicos (álcool, tabaco, medicamentos etc.) ou psicológicos (estresse, ansiedade etc.). Para se adaptar a tais situações, o organismo humano possui um conjunto de mecanismos para controlar o seu equilíbrio interno. Falhas nestes mecanismos de controle podem levar a distúrbios internos ou a importantes problemas de saúde (Fuller, 1977). O cérebro é o responsável, de modo geral, por nossa regulação interna, recebendo informações diversas e enviando "sinais" de controle para o corpo, garantindo assim o nosso bem-estar, mesmo em situações variáveis e inesperadas (Basmajian, 1989; Caballo, 2007).

Diversos autores postulam que, a partir da integração da mente com o corpo uma pessoa consiga controlar diversos fenômenos fisiológicos e biológicos de seu organismo, isto é, se autorregular em busca de uma vida mais saudável (Bray, 1995; Caballo, 2007; Peper et al., 1983; Rockstroh et al., 1989; Schwartz e Andrasik, 2003; Wolf e Binder-MacLeod, 1989). A técnica de biofeedback surge suportada por aqueles estudos como um elemento de apoio ao tratamento, para permitir que o paciente, de forma voluntária ou indireta, possa aprender a controlar diversos parâmetros fisiológicos do organismo. Para tanto, necessita-se de algum meio que forneça ao indivíduo informações biológicas (tensão muscular, temperatura da pele, atividade cerebral, frequência cardíaca etc.) e psicofisiológicas (grau de estresse, relaxamento, excitação, ansiedade etc.) que o mesmo não poderia inferir diretamente. Este meio pode ser constituído desde um simples espelho a um sofisticado aparelho eletrônico. O importante é que ele forneça subsídios (sensitivos) imediatos para a pessoa saber o que ocorre em seu corpo em um determinado momento. De posse da informação recebida, o indivíduo pode realizar um treinamento de autoregulação, tentando atingir um padrão desejável. Neste sentido, o tipo de informação avaliada define o que se denomina modalidade ou categoria de biofeedback, que pode utilizar, por exemplo, frequência respiratória, temperatura da pele, atividade eletromiográfica, atividade eletroencefalográfica ou resposta galvânica da pele, sendo que a escolha de uma determinada modalidade depende do problema que será tratado durante a terapia (Mulholland, 1995; Nikishena et al., 2004; Palsson e Pope, 2002; Rockstroh et al., 1989). De uma forma geral, as aplicações das técnicas de biofeedback tratam de (Chen et al., 1997; 2002; Cho et al., 2002; Critchley et al., 2001; Cruz, 2003; Graap e Freides, 1998; Jafarova e Shtark, 1998; Meagher et al., 1998):
- Manifestações de estresse, estafa e síndrome de fadiga crônica;

- Quadros de ansiedade, fobia, síndrome do pânico, distúrbios obsessivo-compulsivo;

- Distúrbios de aprendizagem, em especial os desvios de déficit de atenção com ou sem hiperatividade;

- Disfunção temporomandibular;

- Enxaqueca;

- Depressão e ansiedade;

- Reabilitações neuromotoras; e

- Incontinência fecal e urinária.

Atualmente, podemos encontrar diversos sistemas de biofeedback no mercado. Entretanto, verifica-se que, apesar dos recursos computacionais utilizados, tais sistemas, em geral, possuem preços elevados e não satisfazem completamente as necessidades dos usuários, são limitados em suas opções/modalidades, nem sempre são de fácil operação, com navegação confusa, feedback não atrativo e não permitem o armazenamento de dados para futuros relatórios. Além disso, o biofeedback apresentado ao terapeuta, em sua maioria, não é completo, com a mera plotagem de gráficos, sem apresentar, por exemplo, análises estatísticas acerca das informações coletadas que, por sua vez, podem conter valiosas informações sobre o andamento da sessão e da terapia como um todo.

Neste contexto, este artigo descreve o projeto de um sistema computacional em tempo real para biofeedback multimodal, em que as informações biológicas ou psicofisiológicas do paciente são detectadas por sensores específicos e processadas para prover feedback visual, em ambientes virtuais tridimensionais, e feedback auditivo. Todos os dados coletados durante as sessões de biofeedback são armazenados em bancos de dados específicos, possibilitando a geração de relatórios para o terapeuta e permitindo o acompanhamento da evolução dos pacientes ao longo do tratamento.

\section{Materiais e Métodos}

O sistema foi projetado para detectar, coletar, processar e fornecer o feedback por meio de ambientes multimídia e tridimensionais, dos seguintes sinais biomédicos: eletromiografia (EMG), eletroencefalografia (EEG), resposta galvânica da pele (GSR), temperatura, frequência respiratória e frequência cardíaca (BPM). A Figura 1 mostra o diagrama de blocos com as unidades básicas do sistema:

- Estágio de detecção: composto pelos eletrodos de detecção próprios para cada tipo de sinal a ser captado (EMG, EEG e GSR) ou pelos sensores específicos para os demais sinais (temperatura, respiração ou BPM); 


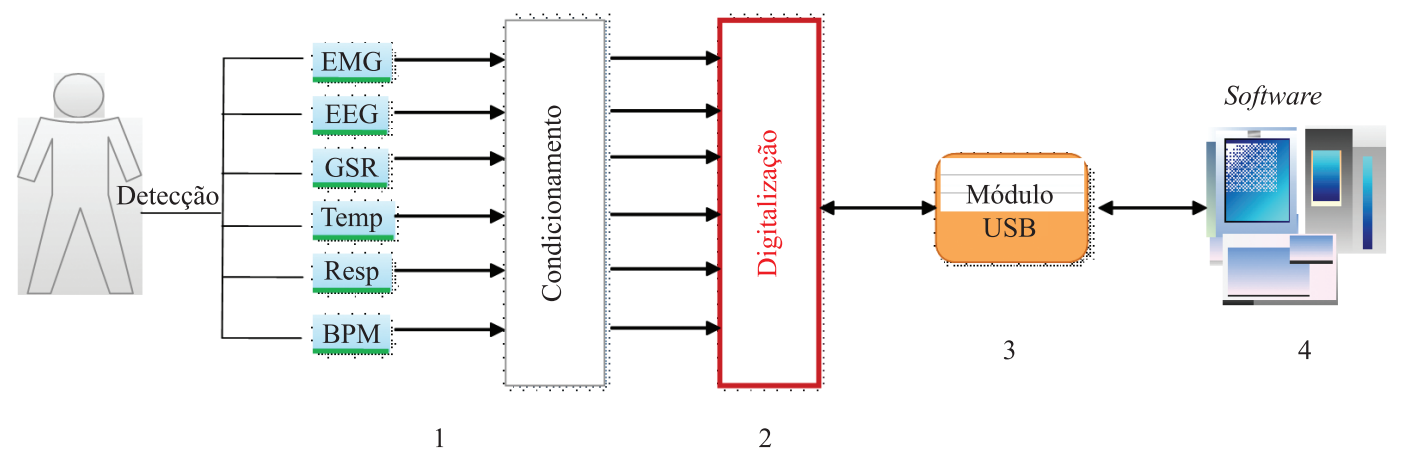

Figura 1. Diagrama de blocos geral do sistema de biofeedback multimodal. Figure 1. General block diagram of the multimodal biofeedback system.

- Condicionamento: unidades responsáveis pelo condicionamento em hardware (amplificadores e filtros cujas especificações são apresentadas adiante);

- Digitalização: responsável pela amostragem e retenção simultânea dos vários sinais, bem como pela conversão analógico/digital dos mesmos;

- Interface USB: para comunicação entre a unidade de hardware e o software host; e

- Software: responsável pelo controle do hardware, coleta e processamento de dados, implementação das terapias de biofeedback em ambientes tridimensionais virtuais.

\section{Hardware}

$\mathrm{O}$ equipamento para a coleta, condicionamento e digitalização dos sinais foi projetado para reduzir ao máximo a necessidade de intervenções por parte do usuário. O módulo de deteç̧ão é composto por sensores de superfície e um circuito de condicionamento específico para cada tipo sinal:

- Eletromiografia (miofeedback) - Esta unidade foi projetada para captação diferencial, em dois canais (EMG1 e EMG2), de sinais provenientes de um par de eletrodos passivos (padrão Beckman $\mathrm{Ag} / \mathrm{AgCl}$ ). Para possibilitar a avaliação de músculos diversos, com intensidades de sinal variáveis, o circuito de amplificação foi projetado para permitir ganhos de $1.000 \times, 2.000 \times, 4.000 \times$ ou $10.000 \times$. Em seguida, o sinal é enviado a um filtro passa-faixa Butterworth de três polos, com banda de passagem entre $15 \mathrm{~Hz}$ e $1 \mathrm{kHz}$. Por fim, a envoltória do sinal é obtida por meio da retificação em onda completa do sinal, seguida de uma nova filtragem analógica (filtro passa-baixa Butterworth de dois polos, com frequência de corte de $10 \mathrm{~Hz}$ );
- Resposta Galvânica da Pele (biofeedback eletrodérmico) - Para o monitoramento da impedância da pele, o equipamento utiliza dois sensores metálicos fixados, por meio de fita 'velcro', nas extremidades dos dedos da mão do paciente (em geral nas falanges médias dos dedos indicador e médio). O sinal GSR captado pelos eletrodos é resultante da aplicação de uma corrente contínua com intensidade variando entre $70 \mu \mathrm{A}$ e $130 \mu \mathrm{A}$ (fonte de corrente ajustável) de acordo com o ganho desejado. Em seguida, o sinal de tensão resultante é amplificado de $1.600 \times$ e filtrado (filtro passa-baixa Butterworth de dois polos, com frequência de corte em $10 \mathrm{~Hz}$ );

- Eletroencefalografia (neurofeedback) - Da mesma forma que a unidade EMG, esta unidade foi projetada para captação diferencial, em dois canais (EEG1 e EEG2), de sinais provenientes de um par de eletrodos passivos (padrão Beckman $\mathrm{Ag} / \mathrm{AgCl}$ ), posicionados na região do escalpo de interesse para a sessão. O circuito de amplificação permite ganhos de $10.000 \times$, $20.000 \times, 40.000 \times, 100.000 \times$ ou $150.000 \times$. Uma vez amplificado, o sinal é filtrado por meio de um filtro passa-faixa Buterworth de três polos, com banda de passagem entre $0,16 \mathrm{~Hz}$ e $30 \mathrm{~Hz}$. Esta faixa de frequências é adequada para a maioria das sessões de neurofeedback descritas na literatura (Basmajian, 1989; Bray, 1995; Chen et al., 1997; Fuller, 1998);

- Frequência cardíaca (biofeedback BPM/ Pletismográfico) - Para a detecção da frequência cardíaca, o equipamento utiliza um sensor padrão utilizado para oximetria de pulso posicionado na ponta de um dos dedos da mão. Os diodos são estimulados a uma frequência de $1 \mathrm{kHz}$ por meio de um CI temporizador LM555. O sinal pulsátil detectado pelos fotodiodos é enviado a um 
filtro Butterworth passa-faixa de dois polos, com frequências de corte de $0,2 \mathrm{~Hz}$ e $30 \mathrm{~Hz}$. Desta forma, os níveis CC e o sinal pulsátil de $1 \mathrm{kHz}$ são eliminados, restando apenas as flutuações resultantes da pulsação cardíaca, que podem ser facilmente detectadas pelo software.

- Temperatura (biofeedback térmico) - Para realizar a medição da temperatura da pele, o sistema utiliza um sensor de temperatura NTC, o qual deve ser fixado no dorso da mão do paciente. O sinal captado pelo eletrodo é amplificado $4 \times$ e é em seguida filtrado para eliminar interferências (filtro Butterworth passa-baixas de dois polos, sintonizado em $5 \mathrm{~Hz}$;

- Frequência Respiratória (biofeedback respiratório) - Um sensor de temperatura NTC, análogo ao utilizado para a medição de temperatura, é utilizado para a monitoração da frequência respiratória. Este deve ser posicionado próximo à narina do paciente, de modo que será resfriado no momento da inspiração e aquecido durante a expiração. O sinal captado pelo eletrodo é amplificado $4 \times$ e é em seguida filtrado para eliminar interferências (filtro Butterworth passa-baixas de dois polos, sintonizado em $5 \mathrm{~Hz}$ ).

A digitalização dos seis sinais (conversão analógico-digital) é realizada por meio de um microcontrolador PIC16F877/040P (Microchip Technology Inc.), com as seguintes características: a) Resolução: 10 bits; b) Fundo de escala analógica: 0 a 5 V; c) Tempo de conversão: $10 \mu$ s; d) Taxa de amostragem: envoltória do sinal $\mathrm{EMG}=240 \mathrm{~Hz}$; $\mathrm{EEG}=240 \mathrm{~Hz} ; \mathrm{GSR}=100 \mathrm{~Hz}$; frequência cardíaca $=240 \mathrm{~Hz}$; temperatura $=100 \mathrm{~Hz}$; frequência respiratória $=100 \mathrm{~Hz}$. O processo de aquisição de dados é totalmente controlado pelo software principal.
Para comunicação entre o aplicativo principal, executando em um microcomputador padrão IBM-PC, e o software embarcado no microcontrolador, o sistema utiliza uma interface bidirecional USB, disponibilizada por meio de um módulo USB específico (DLP Design Inc., modelo DLP-USB245M). Esta interface é fornecida com um conjunto de bibliotecas que podem ser associadas ao software por meio de bibliotecas de ligação dinâmica (DLL). O dispositivo possui um protocolo de transmissão embarcado, de fácil operação, um buffer FIFO com capacidade para 8 kB de dados e possibilita uma taxa de transmissão de dados bidirecional de até $1 \mathrm{MB} / \mathrm{s}$. Tais características são absolutamente adequadas para as taxas de transmissão necessárias ao controle do hardware e para a aquisição em tempo real das informações a serem processadas pelo software principal.

\section{Software}

O software foi implementado na plataforma Windows ${ }^{\circledR}$, utilizando o paradigma de orientação a objetos e a ferramenta de desenvolvimento Visual $\mathrm{C}^{++}$. Para implementação dos ambientes multimídia e tridimensionais, foi utilizada a biblioteca Direct $\mathrm{X}^{\circledR}$ SDK MS-Windows e o software 3D Studio Max ${ }^{\circledR}$. O aplicativo geral (Figura 2) tem por função executar a aquisição e plotagem dos sinais na interface de apoio utilizada pelo terapeuta, realizar análises dos sinais nos domínios do tempo e da frequência (conforme a modalidade de biofeedback em uso) e renderizar os ambientes 3D (terapias).

Para realizá-las corretamente, e em tempo real, é necessária a utilização de técnicas de programação concorrente. A Figura 3 mostra o esquema básico dos processos concorrentes (threads) e dos bancos de memória (buffers) utilizados para a execução das tarefas descritas anteriormente.

A thread Aquisição coleta os dados da porta USB e armazena-os no buffer 1. Esta unidade estabelece um
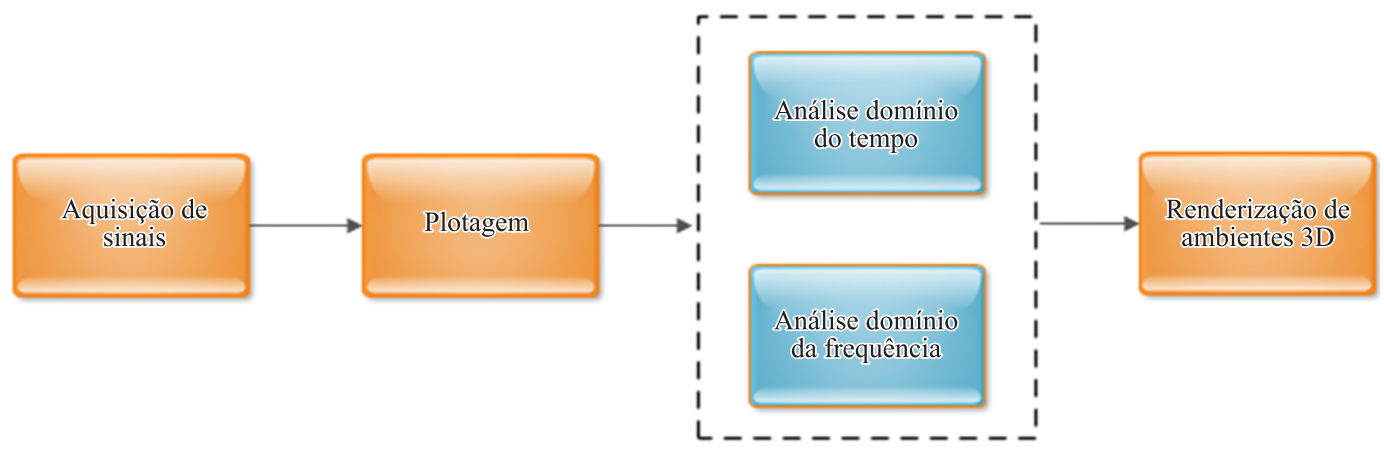

Figura 2. Unidade principais do aplicativo de software.

Figure 2. Main units of software. 


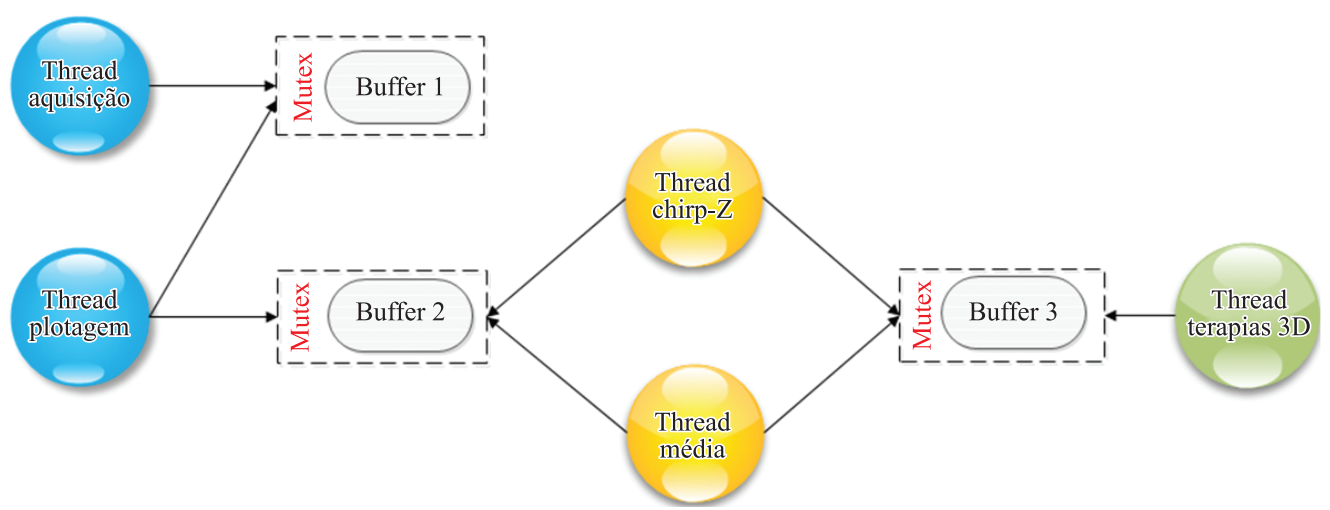

Figura 3. Unidades (threads e outros dispositivos) de concorrência desenvolvidas para permitir o processamento e o feedback em tempo real para as diversas modalidades de biofeedback propostas.

Figure 3. Concurrent programming implemented in the developed software. Concurrent units (threads and other devices) designed to allow real-time processing and feedback to the various modalities of biofeedback proposed.

protocolo de comunicação com o microcontrolador embarcado no hardware responsável pela digitalização dos sinais. A thread Plotagem acessa os dados do buffer 1, plota em um determinado gráfico para permitir a monitoração dos sinais de interesse durante a terapia e os descarrega no buffer 2, para que sejam utilizados por outros processos concorrentes.

A thread Chirp-Z acessa os dados do buffer 2, calcula o espectro de potência do sinal em análise utilizando a transformada Chirp-Z (Soares et al., 20002), apresenta o gráfico na interface de apoio utilizada pelo terapeuta e armazena o conteúdo espectral no buffer 3, para controle do processo de feedback da terapia em curso (controle dos elementos dos ambientes 3D). De modo análogo, a thread Media calcula as médias do sinal (média amostral e RMS), apresenta os resultados na interface de apoio utilizada pelo terapeuta e os armazena no buffer 3, para controle do processo de feedback da terapia em curso. Para permitir que o feedback seja executado em tempo real, as análises dos sinais nos domínios do tempo e da frequência são realizadas em janelas de tempo sequenciais, com duração de $100 \mathrm{mS}$ cada. A thread Terapias coleta os dados do buffer $3 \mathrm{e}$, com base nos mesmos, ajusta os elementos do ambiente 3D (visuais e sonoros) para feedback ao paciente. Outro aspecto importante em relação ao sistema concorrente, é a necessidade do uso de dispositivos para controle dos recursos compartilhados (buffers) simultaneamente pelas threads. Tal controle exige a utilização de estruturas (mutexes) cujo objetivo é garantir a integridade dos dados durante $\mathrm{o}$ acesso feito por tarefas (threads) são executadas num ambiente multitarefa (concorrente).

Para o desenvolvimento das terapias responsáveis pelo biofeedback ao paciente, foram criadas três bibliotecas multimídias: Biblioteca de som, Biblioteca de vídeo e Biblioteca 3D.

\section{Biblioteca de som}

Este conjunto de funções foi desenvolvido para possibilitar feedback sonoro ao paciente e proporcionar sons ambientes (de fundo) durante as sessões. Como base para seu desenvolvimento foram utilizadas as bibliotecas DirectMusic e o DirectSound, componentes do pacote Direct $\mathrm{X}^{\circledR}$ 8.0 SDK MS-Windows. As funções projetadas para executar as seguintes tarefas:

- Tocar sons wave e midi;

- Gerenciar a execução de diversos sons simultaneamente; e

- Controlar o volume, distorção, eco etc., conforme sinais de controle gerados a partir da análise dos dados processados pelas threads Chirp-Z e Media.

\section{Biblioteca de vídeo}

Esta biblioteca foi criada para exibir vídeos especialmente selecionados para cada tipo de terapia. A biblioteca DirectShow do Direct ${ }^{\circledR}$ 8.0 SDK MS-Windows foi utilizada como base para o desenvolvimento. Suas principais funções são:

- Exibir vídeos nos formatos avi, mpeg, mpg e mov; e

- Controlar a execução dos vídeos e ajustar texturas 2D e 3D sobre os mesmos, conforme sinais de controle gerados a partir da análise dos dados processados pelas threads Chirp- $Z$ e Media.

\section{Biblioteca 3D}

As funções para manipulação de ambientes e estruturas 3D foram criadas a partir da Direct3D (também componente do Direct $\mathrm{X}^{\circledR} 8.0$ SDK MS-Windows). As funções criadas permitiram importar objetos 3D, criados no ambiente 3D Studio Max, e renderizar cenas 
3D em tempo real. Os objetos 3D foram criados de modo a permitir animações e manipulações diversas (rotação e/ou translação), controladas conforme os sinais de controle gerados a partir da análise dos dados processados pelas threads Chirp-Z e Media.

\section{Ambientes 3D para as terapias de biofeedback}

As diversas bibliotecas desenvolvidas permitiram a geração de dois ambientes virtuais tridimensionais para as sessões de biofeedback: Neblina e Quebra-Cabeça. A escolha do ambiente e do sinal de controle (modalidade) para a terapia dependerá do tipo de tratamento a ser realizado e é de responsabilidade do terapeuta, que atuará conforme o diagnóstico e a evolução do tratamento.

\section{Ambiente neblina}

Neste ambiente, o paciente poderá acompanhar a execução de um vídeo ou a exibição de uma imagem fixa (Figura 4a) que estarão sobrepostos por uma neblina (Figura 4b) cujo nível de transparência (intensidade) será ajustado conforme a diferença entre o set-point (ou meta) estabelecido pelo terapeuta e o nível (no domínio do tempo ou da frequência) do sinal psicofisiológico que está sendo monitorado (EMG, EEG, temperatura, BPM, GSR ou frequência respiratória). Assim, quanto mais distante do set-point o paciente estiver, mais opaca será a neblina e quanto mais próximo, mais transparente. $\mathrm{O}$ sistema permite também ajustes na direção oposta, ou seja, quanto mais distante do set-point o paciente estiver, mais transparente será a neblina. Assim, o paciente poderá seguir as instruções do terapeuta (protocolos de tratamento para relaxamento/concentração etc.) concentrando-se em buscar a melhor visualização do ambiente tridimensional, enquanto elabora estratégias cognitivas pessoais para atingir o objetivo proposto.

\section{Ambiente quebra-cabeça}

No ambiente Quebra-Cabeça, no início da sessão, um quadro se quebra em vários pedaços (Figura 5a), como se fosse um quebra-cabeça espalhado no
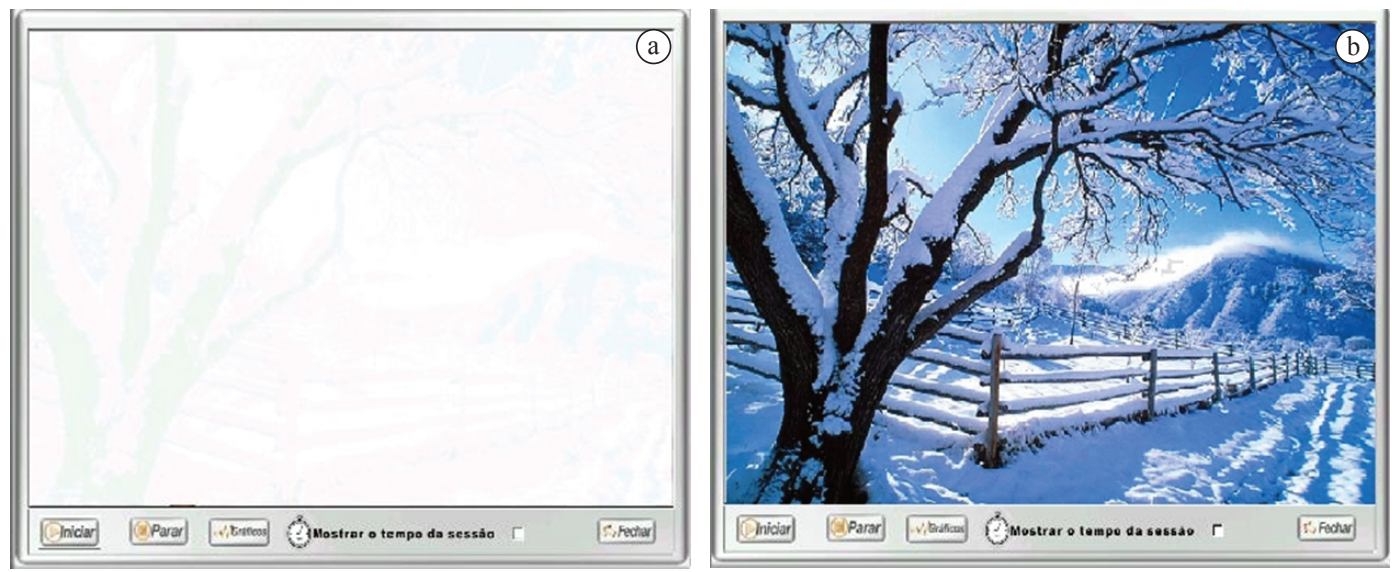

Figura 4. Ambiente Neblina: (a) paciente distante do limiar estabelecido para a sessão de biofeedback; (b) paciente se aproximando do limiar estabelecido.

Figure 4. Fog environment: (a) patient still far from the setpoint established for the biofeedback session; (b) patient approaching the setpoint.
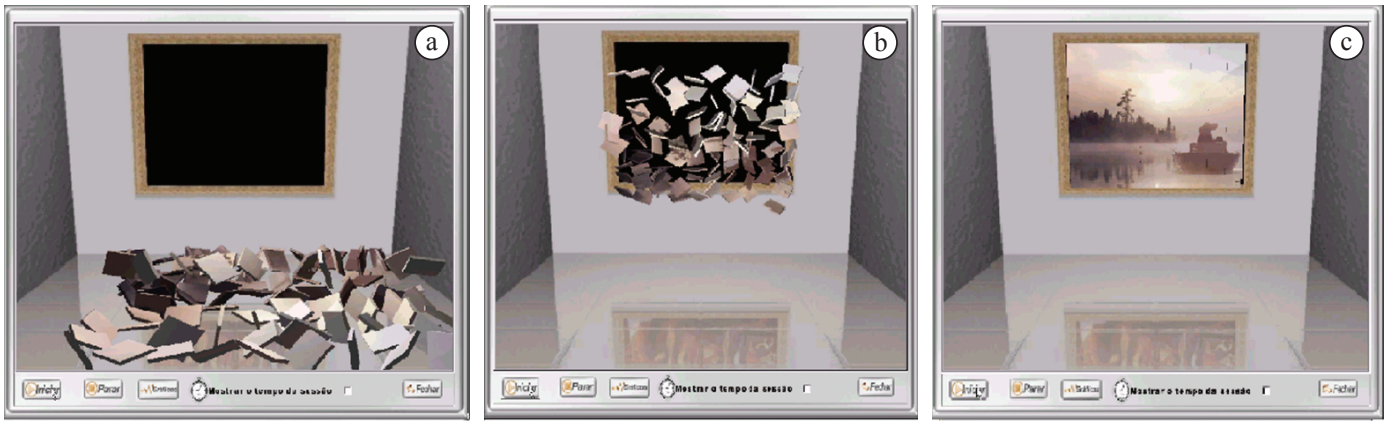

Figura 5. Ambiente Quebra-Cabeça: (a) paciente distante do limiar estabelecido para a sessão de biofeedback; (b) paciente se aproximando do limiar estabelecido; (c) paciente atingiu o limiar definido para a sessão.

Figure 5. Puzzle environment: (a) patient still far from the setpoint established for the biofeedback session; (b) patient approaching the setpoint; (c) patient reaches the setpoint defined for the session. 
chão. Para remontá-lo, o paciente deverá atingir o limiar estabelecido pelo terapeuta (Figuras 5b, c). De modo análogo ao ambiente anterior processo de remontagem do quadro ocorrerá conforme a diferença entre o set-point estabelecido pelo terapeuta e o nível (no domínio do tempo ou da frequência) do sinal psicofisiológico que está sendo monitorado (EMG, EEG, temperatura, BPM, GSR ou frequência respiratória). Assim, quanto mais distante do set-point o paciente estiver, mais espalhadas estarão as peças do quebra-cabeça e quanto mais próximo, mais peças serão remontadas no quadro. O sistema permite também ajustes na direção oposta, ou seja, quanto mais distante do set-point o paciente estiver, mais peças serão remontadas no quadro. Assim, o paciente poderá seguir as instruções do terapeuta (protocolos de tratamento para relaxamento/concentração etc.) concentrando-se em buscar a remontagem do quadro no ambiente tridimensional, enquanto elabora estratégias cognitivas pessoais para atingir o objetivo proposto.

\section{Funções de apoio}

Para facilitar o acompanhamento e a evolução do paciente durante o tratamento com biofeedback, o sistema foi projeto para realizar ainda as seguintes tarefas:

- Cadastro de pacientes - Armazenamento dos dados pessoais, antropométricos, clínicos, anamnese e informações sobre o tratamento proposto;

- Armazenamento das sessões realizadas - Todos os sinais coletados durante a sessão e outras informações de interesse do terapeuta (comentários e anotações) são armazenados em arquivo;

- Geração de relatórios - O aplicativo permite a geração de diversos relatórios referentes a todas as sessões realizadas ou a uma sessão específica. Os relatórios apresentam estatísticas sobre a evolução do paciente numa sessão ou entre várias sessões (RMS, variância, desvio padrão, valores máximo e mínimo etc.).

A Figura 6a mostra a interface principal do aplicativo em que o usuário pode optar por iniciar um novo protocolo de tratamento em biofeedback (cadastro de pacientes e terapias) ou carregar os dados de pacientes já cadastrados para continuar um protocolo de tratamento. A Figura $6 \mathrm{~b}$ apresenta a interface padrão para configuração das sessões de biofeedback (apesar da tela capturada mostrar apenas "Peças" (ambiente Quebra-Cabeça), os mesmos elementos são utilizados para o ambiente Neblina). Na tela de configuração o usuário pode: (i) selecionar a imagem ou o vídeo a ser mostrado durante a sessão; (ii) selecionar o tipo de sinal (modalidade) que controlará a montagem do quebra-cabeça ou a intensidade da neblina; (iii) o som (música) de fundo a ser executado durante a sessão; (iv) o limiar de base (linha de base) a partir do qual a sessão irá se desenvolver; e (v) a meta (limiar) a ser atingida durante a sessão.

\section{Resultados}

O desempenho geral do sistema foi avaliado por meio experimentos específicos para as várias modalidades de biofeedback implementadas. Contudo, deve-se ressaltar que tais experimentos tiveram como objetivo verificar apenas o desempenho do sistema hardwarel software e suas características operacionais e de usabilidade. A seguir, são descritos os resultados de três sessões experimentais, com dois ambientes multimídia e diferentes objetivos terapêuticos: reforço de ondas EEG alfa (neurofeedback), reforço muscular (biofeedback EMG) e relaxamento (biofeedback GSR). Todos os demais experimentos realizados para as demais modalidades de biofeedback apresentaram resultados similares aos apresentados.
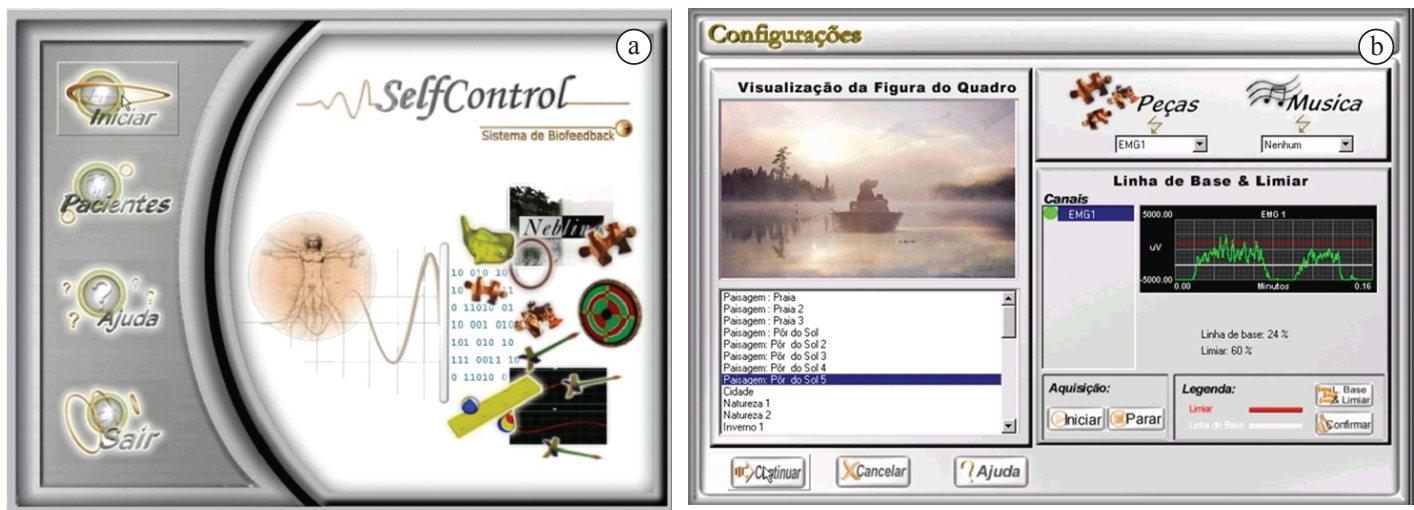

Figura 6. Interfaces principais do aplicativo: a) interface de entrada; e b) interface de configuração das sessões de biofeedback. Figure 6. Main user interfaces: a) initial interface; and b) interface to configure the various aspects of biofeedback session. 


\section{Sessão de neurofeedback}

- Preparação da sessão - O voluntário foi posicionado sentado confortavelmente em uma poltrona em frente à tela do computador. Para captação do sinal EEG foram utilizados eletrodos passivos tipo Beckman $\mathrm{Ag} / \mathrm{AgCl}$ (Figura 7a): eletrodos de captação posicionados em Cz e A2 (padrão EEG 10-20); eletrodo de referência posicionado no lóbulo da orelha direita (A1).

O ambiente 3D Quebra-Cabeça foi selecionado para a sessão, que teve como objetivo auxiliar o usuário a elevar a intensidade de ondas alfa no padrão de atividade cortical - protocolo comum em terapias de neurofeedack para tratamento de hiperatividade e déficit de atenção (Schwartz e Andrasik, 2003). Para definição do set-point da sessão (Figura 7b), tomou-se, inicialmente, medidas da linha de base, ou seja, a intensidade do padrão de ondas EEG alfa (8-13 Hz) pré-sessão. Este valor é então usado como valor base, a partir do qual o voluntário deve progredir durante a sessão. Um limiar de $+20 \%$ da linha de base foi definido como patamar a ser atingido na sessão (o voluntário deve se concentrar até que a intensidade da onda alfa fosse elevada em $20 \%$ do valor inicial).
- A sessão de neurofeedback - A sessão experimental se inicia com a exibição do ambiente Quebra-Cabeça, com as peças de um quadro posicionadas no chão virtual. A tarefa do voluntário é buscar estratégias para aumentar seu nível de concentração, elevando a intensidade da onda EEG alfa até o limiar definido. À medida que o padrão de concentração se eleva o quadro começa a se remontar, caso contrário, ele se desmancha novamente. Esta "remontagem" dinâmica e proporcional à intensidade das ondas EEG alfa é o que caracteriza o feedback visual, fundamental para apoiar o voluntário a desenvolver uma estratégia adequada para elevar seu nível de concentração.

A Figura $7 \mathrm{c}$ mostra a evolução da atividade neural durante a sessão de neurofeedback. Esta interface é visualizada apenas pelo terapeuta, para que possa avaliar se suas estratégias de apoio ao paciente (reforços verbais, protocolos etc.) estão surtindo o efeito desejado. Nesta janela pode-se observar, em um gráfico $3 \mathrm{D}$, a evolução do conteúdo espectral do sinal EEG ao longo do tempo e outras medidas estatísticas calculadas em tempo real.
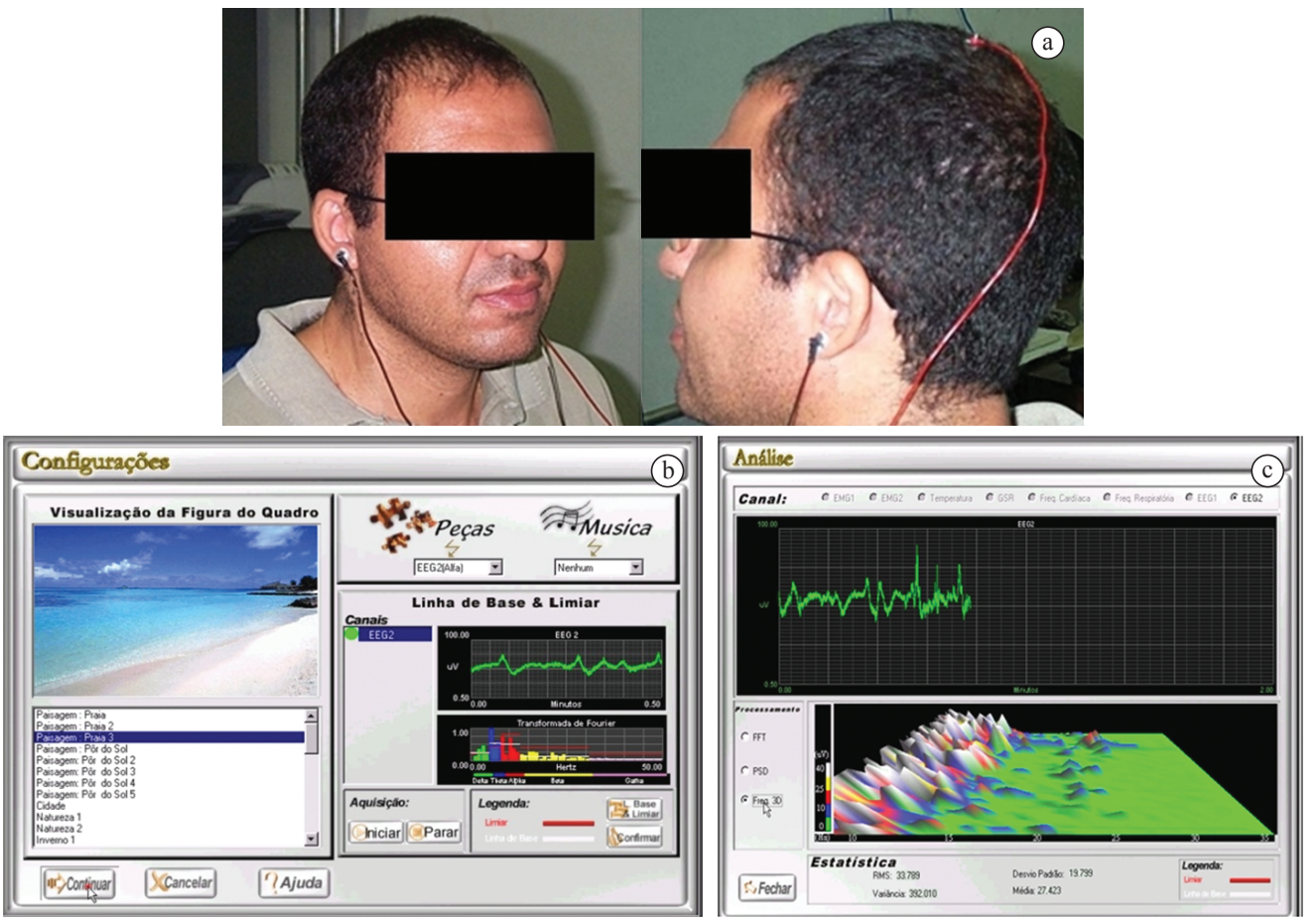

Figura 7. Sessão de neurofeedback: (a) posicionamento dos eletrodos de captação; (b) tela de configuração; e (c) evolução da atividade neural durante a sessão, em gráfico 3D do conteúdo espectral do sinal EEG (frequência $\times$ energia $\times$ tempo) e medidas estatísticas calculadas em tempo real.

Figure 7. Neurofeedback session: (a) positioning of the electrodes; (b) configuration/setup interface; and (c) evolution of the neural activity during the session $-3 D$ graph of the spectral energy distribution of the EEG signal (frequency $\times$ energy $\times$ time) and statistics calculated in real time. 


\section{Sessão de miofeedback para reforço muscular}

- Preparação da sessão - A voluntária foi posicionada sentada confortavelmente em uma poltrona em frente à tela do computador. Para captação do sinal EMG foram utilizados eletrodos passivos tipo Beckman $\mathrm{Ag} / \mathrm{AgCl}$, posicionados sobre o ventre do músculo bíceps braquial (cabeça longa), com distância intereletrodos de $15 \mathrm{~mm}$. O eletrodo de referência foi posicionado sobre o punho. $\mathrm{O}$ ambiente 3D Quebra-Cabeça foi selecionado para a sessão. O limiar de $70 \%$ da contração isométrica voluntária máxima (CIVM) foi definido como patamar a ser atingido na sessão.

- A sessão de miofeedback - Durante a sessão experimental, a voluntária visualiza o ambiente Quebra-Cabeça, com as peças de um quadro posicionadas no chão virtual. A tarefa da voluntária é então remontar a imagem aumentando o nível de contração muscular do bíceps até o limiar definido. À medida que o sinal EMG se aproxima do limiar estabelecido o quadro começa a se remontar, caso contrário, ele se desmancha novamente.

A Figura 8 mostra of feedback visual fornecido à voluntária. Notar que na Figura 8a a voluntária está executando uma contração muscular em direção ao limiar estabelecido e, consequentemente, as peças do quebra-cabeça estão retornando ao local de origem. $\mathrm{Na}$ Figura $8 \mathrm{~b}$ a voluntária já atingiu praticamente $100 \%$ do limiar desejado e a grande maioria das peças já se encontra encaixada no quadro.

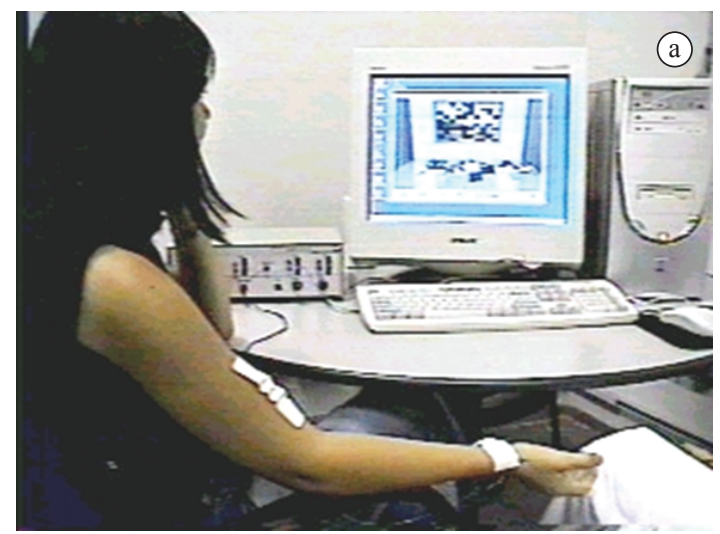

\section{Sessão de biofeedback eletrodérmico para relaxamento}

- Preparação da sessão - A voluntária foi posicionada sentada confortavelmente em uma poltrona em frente à tela do computador. Para captação do sinal de resposta galvânica da pele (resposta eletrodérmica ou GSR) foram utilizados eletrodos passivos tipo Beckman $\mathrm{Ag} / \mathrm{AgCl}$, posicionados nas falanges médias dos dedos indicador e médio da voluntária. $\mathrm{O}$ ambiente 3D Neblina foi selecionado para a sessão. Para definição do set-point da sessão, tomou-se inicialmente medidas da linha de base, ou seja, a intensidade do sinal GSR pré-sessão. Este valor é então usado como valor base, a partir do qual a voluntária deve progredir durante a sessão. Um limiar de $-20 \%$ da linha de base foi definido como patamar a ser atingido na sessão (a voluntária deveria relaxar até que a intensidade do sinal GSR fosse reduzida para $80 \%$ do valor inicial).

- A sessão de biofeedback eletrodérmico (GSR) - Nesta sessão, a voluntária visualiza o ambiente um vídeo encoberto por uma "neblina". À medida que a voluntária relaxa e o sinal GSR se aproxima do limiar estabelecido, a "neblina" desaparece proporcionalmente; caso contrário, a "neblina" é intensificada.

A Figura 9 mostra o feedback visual fornecido à voluntária. Notar que na Figura 9a a voluntária está ainda muito acima do nível de relaxamento desejado e, consequentemente, a "neblina" encobre toda a imagem. À medida que seu nível de relaxamento se aproxima do limiar estabelecido a "neblina" se

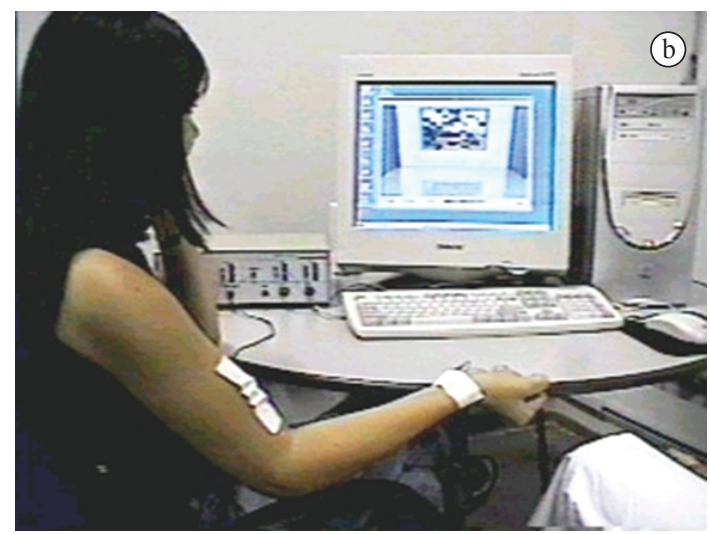

Figura 8. Feedback fornecido à voluntária em sessão de miofeedback: (a) voluntária iniciando a contração muscular e se aproximando do limiar desejado; (b) voluntária em fase mais avançada, aumentando o padrão de contração e se aproximando ainda mais do limiar desejado. Figure 8. Feedback provided to the volunteer during a myofeedback session: (a) the volunteer initiating muscle contraction and approaching the established baseline for the session; (b) the volunteer in a more advanced stage, increasing the muscle contraction and getting even closer to the established baseline. 

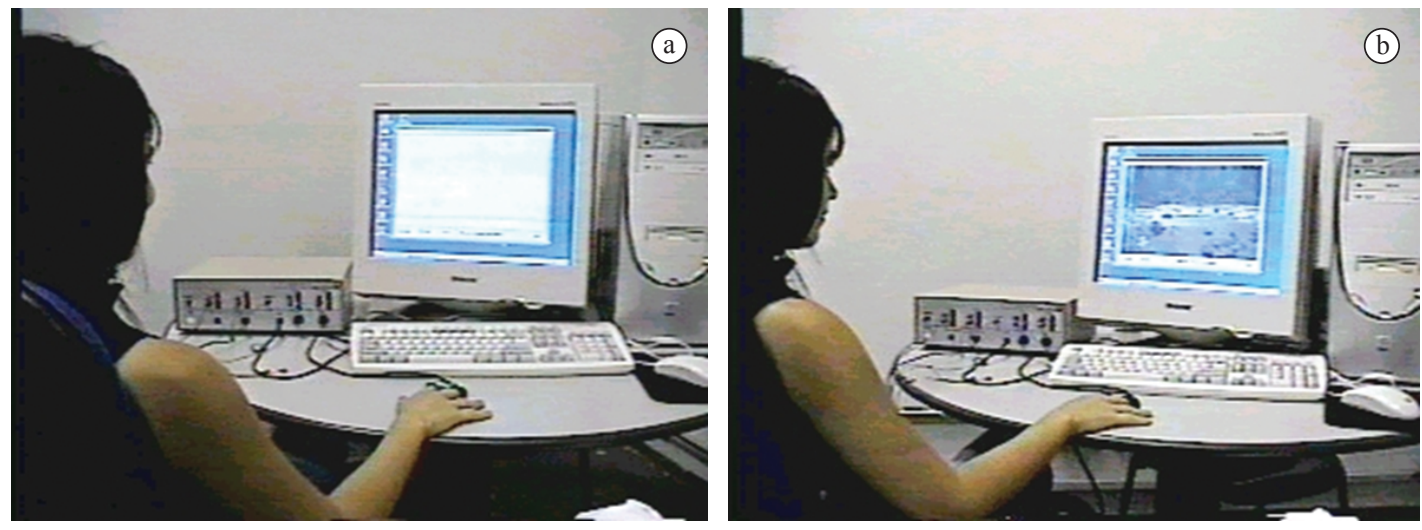

Figura 9. Feedback fornecido à voluntária em sessão de biofeedback eletrodérmico: (a) voluntária fora do padrão desejado; (b) voluntária atingindo o padrão determinado.

Figure 9. Feedback provided to the volunteer during a GSR biofeedback session: (a) the volunteer getting out of the established baseline during the therapy session; (b) the volunteer reaching in the established baseline.

dissipa, permitindo a visualização completa do vídeo em exibição (Figura 9b). Estas mudanças dinâmicas na imagem, proporcionais à intensidade do sinal GSR (que, por sua vez, está diretamente correlacionado ao nível de excitação/estresse), é o que caracteriza o feedback visual, essencial para apoiar a voluntária a desenvolver uma estratégia adequada para relaxamento.

\section{Discussão}

Conforme descrito anteriormente, os experimentos foram realizados com o objetivo de verificar o desempenho e a dinâmica operacional em sessões de biofeedback padrão. Neste sentido, os testes realizados nas diversas modalidades para as quais o sistema foi projetado mostraram que os usuários (terapeutas) puderam operá-lo de forma intuitiva, rápida e segura, em grande parte creditada ao fato da inexistência de menus de opções nas interfaces do aplicativo, o que facilitou consideravelmente a sua navegação. Em todas as interfaces, as configurações necessárias para cada sessão, em cada uma das modalidades disponíveis, são apresentadas sequencialmente ao usuário. Tal estratégia impediu o acesso indevido a configurações não associadas à sessão em andamento, bem como evitou confusões (i.e., esquecer-se de realizar determinado ajuste ou calibração) causadas por menus diversos distribuídos pela interface (comuns nos aplicativos de biofeedback atuais).

O experimento na modalidade neurofeedback, baseado no ambiente Quebra-Cabeça e projetado para reforço de ondas EEG alfa (protocolo padrão para tratamento de hiperatividade e déficit de atenção), mostrou que os usuários (terapeutas) não tiveram qualquer dificuldade para manuseio do sistema hardware/software (conexões, calibrações e configurações). Da mesma forma, o voluntário não reportou qualquer dificuldade para interagir com o sistema e considerou que as "pistas" mostradas pelo software foram extremamente úteis para que atingisse com facilidade a meta definida para a sessão.

Durante o experimento de miofeedback com o ambiente Quebra-Cabeça, a voluntária relatou grande facilidade para compreender sua interação com o sistema e podia perceber claramente quando ela estava se aproximando ou se afastando do padrão estabelecido para a sessão e, assim, buscar as melhores estratégias para atingir sem muita dificuldade o limiar desejado. Da mesma forma, no experimento de biofeedback eletrodérmico com o ambiente Neblina, a voluntária não relatou qualquer dificuldade em relação à dinâmica $\mathrm{e}$ ao controle da sessão. A "neblina" aparecendo quando ela estava se afastando do padrão estabelecido ou se dissipando quando ela se aproximava do padrão, mostrou sre um elemento simples e intuitivo para feedback.

\section{Conclusão}

Os diversos experimentos realizados permitiram concluir que o sistema apresentou desempenho conforme especificado e é adequado para sessões de biofeedback multimodal, com grande potencial para aplicação em diversos tratamentos.

De forma geral, os elementos principais observados no sistema hardware/software proposto, e que o distingue dos demais encontrados no mercado e na literatura são: (i) a extrema facilidade de operação, sem o uso intenso e comum de menus e submenus que, muitas vezes, são de manuseio não intuitivo, podendo ficar escondidos em diversos subníveis e dificultando sobremaneira a execução de operações como configuração e calibração das sessões; (ii) o sistema de controle e configuração é automatizado, 
levando passo a passo o usuário apenas aos elementos de interface que exijam sua atenção/ação; (iii) um robusto sistema de banco de dados que permite aos terapeutas acompanharem todo o desenvolvimento dos pacientes durante o tratamento e, desta forma, confirmarem se sua conduta está sendo adequada ou se deve ser ajustada para cada paciente; e (iv) a possibilidade de desenvolver as principais modalidades de biofeedback (inclusive mais que uma por terapia - multimodal) em um mesmo dispositivo hardware/software.

Por fim, deve-se destacar que os autores já iniciaram os desenvolvimentos para aprimoramento do protótipo, que deverão incorporar novos ambientes de feedback baseados em Realidade Virtual e Aumentada, de modo a permitir a imersão dos pacientes em ambientes cada vez mais interativos e, com isso, ampliar as potencialidades terapêuticas do sistema (estas inovações serão objeto de publicações futuras).

\section{Referências}

Basmajian JV. Biofeedback: Principles and practice for clinicians. 3rd ed. Baltimore: Williams \& Wilkins; 1989.

Bray D. Biofeedback. In: Rankin-Box D, editor. The nurses' handbook of complementary therapies. 2nd ed. Edinburgh: Baillière Tindall;1995. p. 65-73.

Caballo VE. Manual de técnicas de terapia e modificação do comportamento. 2nd ed. Rio de Janeiro: Editora Santos; 2007.

Chen D, Sadeghi S, Mann S. On the design of HI-based biofeedback interfaces. In: 2002 IEEE SMC: Proceedings of the International Conference on Systems, man and Cybernetics; 2002 Oct 6-9; Hammamet, Tunísia. Hammamet; 2002. p. 275-6.

Chen YL, Chen CL, Chang WH, Wong MK, Tung FT, Kuo TS. The development of a biofeedback training system for cognitive rehabilitation in cerebral palsy. In: Engineering in Medicine and Biology Society, 1997: Proceedings of the 19th Annual International Conference of the IEEE - EMBS; 1997 Oct 30-Nov 02; Chicago, USA. Chicago; 1997. p. 1919-20.

Cho BH, Lee JM, Ku JH, Jang DP, Kim JS, Kim IY, Lee JH, Kim SI. Attention enhancement system using virtual reality and EEG biofeedback. In: IEEE VR'02: Proceedings of the IEEE Virtual Reality Conference; 2002 Mar 24-28; Orlando, USA. Orlando; 2002. p. 156-63.

Critchley HD, Melmed RN, Featherstone E, Mathias CJ, Dolan RJ. Brain activity during biofeedback relaxation - A functional neuroimaging investigation. Brain. 2001; 124(5):1003-12. http://dx.doi.org/10.1093/brain/124.5.1003

Cruz CF. Sistema de biofeedback para otimização de movimento de membros superiores de corredores com paralisia cerebral [dissertação]. Campinas: Universidade Estadual de Campinas; 2003.

Fuller GD. Biofeedback: Methods and procedures in clinical practice. San Francisco: Biofeedback Press; 1977.

Graap K, Freides D. Regarding the database for the peniston alpha-theta EEG biofeedback protocol. Applied Psychophysiology and Biofeedback. 1998; 23(4):265-72.

Jafarova O, Shtark M. Computer biofeedback: Trends of development. In: International Conference APEIE - IEEE, 1998: Proceedings of the 4th International Conference on Actual Problems of Electronic Instrument Engineering; 1998 Sep 23-26; Novosibirsk, Russia. Novosibirsk; 1998. p. 162-4.

Meagher AP, Sun WM, Kennedy ML, Smart RC, Lubowsky DZ. Biofeedback for anismus: has placebo effect been overlooked? Colorectal Disease. 1998; 1(2):80-7. http:// dx.doi.org/10.1046/j.1463-1318.1999.00019.x

Mulholland T. Human EEG, behavioral stillness and biofeedback. International Journal of Psychophysiology. 1995; 19(3):263-79.

Nikishena IS, Ponomarev A, Grin-Yatsenko VA, Kropotov YD. Mapping of changes in EEG spectrum power during a session of biofeedback training of the $\beta 1$ rhythm. Human Physiology. 2004; 30(4):392-6. http://dx.doi.org/10.1023/ B:HUMP.0000036330.55489.48

Palsson OS, Pope AT. Morphing beyond recognition: The future of biofeedback technologies. Biofeedback. 2002; 30(1):14-8

Peper E, Ancoli S, Quinn M. Mind/Body integration - essential readings in biofeedback. New York: Plenum Press; 1983.

Rockstroh B, Elbert T, Birbaumer N, Lutzenberger W. Biofeedback-produced hemispheric asymmetry of slow cortical potentials and its behavioral effects. International Journal of Psychophysiology. 1989; 9(2):151-65.

Schwartz MS, Andrasik F. Biofeedback - a practioner's guide. 3rd ed. New York: Guilford Press; 2003.

Soares AB, Berzin F, Andrade AO. A power estimation of EMG signals via Chirp-Z transform. In: ISEK 2002: Proceedings of the XIV Congress of the International Society of electrophysiology and kinesiology; 2002 Jun 22-25; Viena, Austria. Viena; 2002. p. 42-3.

Wolf S L, Binder-MacLeod SA. Neurophysiological factors in electromyographic feedback for neuromotor disturbance. In: Basmajian JV. Biofeedback: Principles and practice for clinicians. 3rd ed. Baltimore: Williams \& Wilkins; 1989.

\section{Autores}

\section{Angela Abreu Rosa de Sá*, Alcimar Barbosa Soares}

Laboratório de Engenharia Biomédica, Faculdade de Engenharia Elétrica, Universidade Federal de Uberlândia - UFU, Av. João Nave de Ávila, 2121, Santa Mônica, CEP 38408-000, Uberlândia, MG, Brasil. 